\title{
Removal of dexamethasone from aqueous solutions using modified clinoptilolite zeolite (equilibrium and kinetic)
}

\author{
S. N. Mohseni ${ }^{1}$ A. A. Amooey ${ }^{1}$ - H. Tashakkorian $^{2}$ - A. I. Amouei ${ }^{3}$
}

Received: 24 November 2015/Revised: 31 May 2016/Accepted: 25 June 2016/Published online: 12 July 2016

(C) Islamic Azad University (IAU) 2016

\begin{abstract}
The aim of this study was to remove a known pharmaceutics, dexamethasone, from an aqueous solution using clinoptilolite zeolite (CP). CP is a natural, versatile and inexpensive mineral, which has been investigated and applied in the last few decades. Herein, the experiments were carried out in the common conditions of a batch system in room temperature, and the effects of some parameters such as $\mathrm{pH}$ of the solution, initial concentration of dexamethasone, adsorbent dose and contact time were studied. Kinetic and isotherm of adsorption processes of dexamethasone on CP were surveyed in the current study. Results revealed that the maximum efficiency (78\%) occurred in $\mathrm{pH}=4$. The adsorption process followed a pseudo-second-order kinetic model as well as Freundlich and Sips isotherm models fitted with the experimental data well.
\end{abstract}

Keywords Dexamethasone - Clinoptilolite zeolite · Removal efficiency $\cdot$ Isotherm and kinetic model

A. I. Amouei

iamouei1966@gmail.com

1 Department of Chemical Engineering, University of Mazandaran, Babolsar, Iran

2 Cellular and Molecular Biology Research Center, Babol University of Medical Sciences, Babol, Iran

3 Environmental Health Research Center, Environmental Health Department, Babol University of Medical Sciences, Babol, Iran

\section{Introduction}

Glucocorticoids are one of the most important groups of pharmaceuticals, which are widely incorporated in the treatment of diseases in humans and animals (Reid 2000; Schäcke et al. 2002). Nowadays, overuse of different pharmaceutics, especially glucocorticoids in hospitals and medical centers, and unfortunately no use of some effective procedures in the treatment of effluents lead to an increase in the concentration of hazardous chemicals in wastewaters (Sui et al. 2010; Herrero et al. 2012). One of the most commonly used glucocorticoids is dexamethasone (Arsand et al. 2013; Herrero et al. 2012). The structures of dexamethasone are presented in Fig. 1. This structure is one of the chemicals which cannot be efficiently removed from hospital wastewater using conventional on-site treatment methods (Schäcke et al. 2002; Sim et al. 2010). Untreated effluents infiltrate into the underground water and finally enter to living organisms bodies (Jafari et al. 2011). Although dexamethasone has extensive effects in the treatment of various diseases, it can cause many adverse effects. This compound leads to some serious health risks such as weakening the immune system and also amplifies the risk of suffering from infectious diseases. Recently, due to the adverse effects that may cause some harsh irreversible problems, the researchers of environmental issues have suggested a variety of techniques for the removal of pharmaceuticals from wastewater (Kummerer 2001; Heberer 2002).

Among the common processes for purification, the removals of contaminants through using the adsorption technology on natural materials have gained much interest during recent decades (Elwakeel and Guibal, 2015a, b; Sharma et al. 2011; Amuda and Ibrahim, 2006). In the adsorption mechanism, attractive forces play the main role 
Fig. 1 Dexamethasone structures

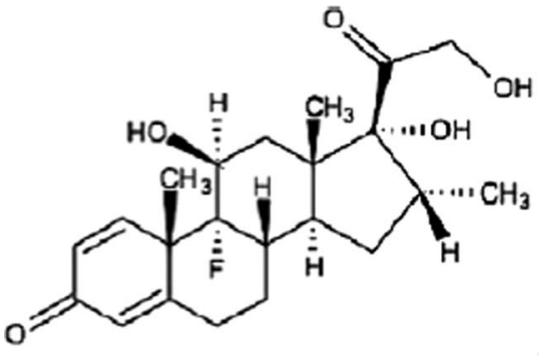

Dexamethasone

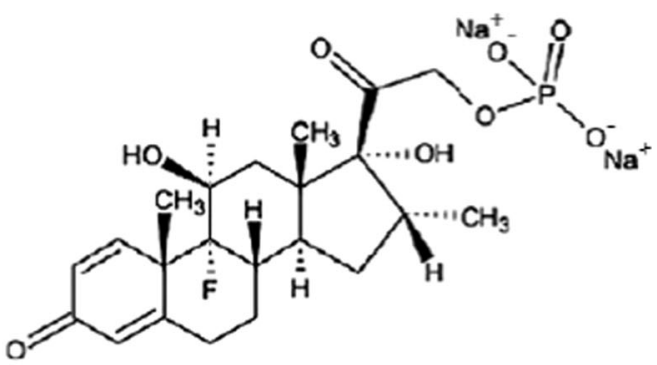

Dexamethasone sodium phosphate between adsorbent and adsorbate functional groups. Intermolecular forces depend on different factors such as nature of adsorbent, adsorbate and contact area.

Natural adsorbents such as agricultural wastes and natural zeolites have been considered as high efficiency and environmental friendly adsorbents (Jaishankar et al. 2014). For instance, a number of studies have been investigated, such as removal of chromium (VI) using sunflower waste (Jain et al. 2009a), adsorption of metal ions by olive waste (Fiol et al. 2006), removal of copper by pine cone shell (Blazquez et al. 2012), $\mathrm{Cu}$ (II) onto coconut shell (Acheampong et al. 2013), cadmium (II) onto loquat leaves and canola residuals (Al-Dujaili et al. 2012; Amouei et al. 2014), thorium by brown algae (Keshtkar and Hassani 2014), removal of $\mathrm{Cu}(\mathrm{II})$ and $\mathrm{Pb}(\mathrm{II})$ by coffee grains (Cerino Cordova et al. 2013).

Natural zeolites which mainly consist of oxygen, silicon and aluminum are abundant and have different kinds. The chemical structure of zeolite consists of $\mathrm{AlO}_{4}{ }^{5-}$ and $\mathrm{SiO}_{4}{ }^{4-}$ units which are linked to each other by sharing oxygen atoms (Wibowo et al. 2011). This unique arrangement provides a special porous structure that has total negative charge. Zeolites have a number of characteristics such as dewatering, ion exchange capacity, low density and removal capability for organic and inorganic pollutants. These properties result in the use of zeolites for the removal of numerous contaminants from aqueous solutions such as cationic surfactants $(\mathrm{Li}$ 2007), basic dyes ( $\mathrm{Li}$ et al. 2015), chromate (Ghiaci et al. 2004), Cr(VI) and As (V) (Yusof and Malek, 2009), cadmium (Vasylechko et al. 2003) and arsenic (Chutia et al. 2009; Malekpour et al. 2009).

Clinoptilolite is one of the most abundant zeolites and can be served in different applications such as aquaculture, agriculture, poultry, environments and medicine (Malekpour et al. 2009) due to cost-effectiveness in view point of industrial usages. The $\mathrm{CP}$ with the high selective affinity uniquely suited to various applications of wastewater treatment.

In this study, $\mathrm{CP}$ with the simplified formula of $\left(\mathrm{K}_{2}\right.$, $\left.\mathrm{Na}_{2}, \mathrm{Ca}, \mathrm{Mg}\right)_{3} \mathrm{Al}_{6} \mathrm{Si}_{30} \mathrm{O}_{72} .24 \mathrm{H}_{2} \mathrm{O}$, specific surface area
$43.91 \mathrm{~cm}^{2} / \mathrm{g}$, pore diameter $0.018 \mu \mathrm{m}$ and pore volume $0.1717 \mathrm{~cm}^{3} / \mathrm{g}$ was evaluated as a novel, inexpensive and efficient natural zeolite for removal of dexamethasone from aqueous solutions in different conditions.

\section{Materials and methods}

\section{Preparation of adsorbent}

In this study, the modified CP is used as natural adsorbent for the removal of dexamethasone from aqueous solutions. For preparation of the adsorbent, the materials were initially washed with distilled water and the dust was removed (Dianati Tilaki et al. 2014). Then, it was crushed into fine particles with an electric mill, and the American Standard Testing and Materials (ASTM) sieves were used finally, particles that were approximately below 500 microns were selected (Vasylechko et al. 2003). In the next step, for removing impurities from the zeolite surface and activation of the zeolite, the materials were washed with a sulfuric acid $2 \mathrm{M}$ solution (Maleki et al. 2015). In this stage, $3 \mathrm{~g}$ of zeolite were added to $100 \mathrm{ml}$ sulfuric acid $2 \mathrm{M}$ solution mixed for $2 \mathrm{~h}$ on a shaker with $180 \mathrm{rpm}$. After $2 \mathrm{~h}$, zeolite particles were filtered using Whatman membrane filter (0.45 microns) and washed several times with distilled water so that the $\mathrm{pH}$ effluent reached to 7 . In the final step, the zeolite powder was placed in an oven (at $100{ }^{\circ}$ Centigrade) for $12 \mathrm{~h}$ to remove moisture, and then, it was placed in the desiccators (Chutia et al. 2009).

\section{Reagents}

The stock solution of sodium phosphate dexamethasone (100 mg/l) was prepared by dissolving dexamethasone (4000 mg/l) in distilled water, and then, the desired concentrations were provided through diluting the stock solution. 


\section{Experimental plan}

Experiments were done in the batch system in a laboratory scale and in room temperature $\left(25^{\circ} \mathrm{C}\right)$. The effects of several parameters such as $\mathrm{pH}$ solution $(4,7,9)$, initial concentration of dexamethasone $(5,10,20,40 \mathrm{mg} / \mathrm{l})$, adsorbent dose $(0.1,0.3,0.5 \mathrm{~g} / 50 \mathrm{ml})$ and contact time (15, $30,45,60,90,120 \mathrm{~min}$ ) were investigated. The nitric acid and sodium hydroxide $2 \mathrm{M}$ solutions were used to adjust the $\mathrm{pH}$ of the solution. A shaker (by speed of $180 \mathrm{rpm}$ ) was used to mix the samples, and after the desired time lapsed, a centrifuge was used to separate the liquid phase from the solid one. After sampling from the liquid phase, the dexamethasone concentration was measured using UV spectrophotometer double beam, PG instrument model. The measurement was taken according to the standard methods of water and wastewater examinations (APHA et al. 2012). All experiments were repeated at least three times, and the relative error was about $2.5 \%$.

\section{Results and discussion}

\section{Effect of pH on adsorption}

In each adsorption process, the $\mathrm{pH}$ of the solution is one of the effective parameters owing to its direct influence on the adsorbent surface properties and ionic forms of contaminant in the solution. The type and ionic state of functional groups on the surface of the adsorbent and adsorbate are important factors that affect the dependence level of the adsorption process on $\mathrm{pH}$. In the present study, for determining the effect of $\mathrm{pH}$ on adsorption efficiency, the adsorption process was performed in three conditions including acidic, neutral and alkaline in $\mathrm{pH} \mathrm{4,7}$ and 9, respectively. As shown in Fig. 2, the removal efficiency of dexamethasone through modified zeolite was increased by decreasing $\mathrm{pH}$ and the maximum removal efficiency was obtained in $\mathrm{pH}=4$.

There is a reverse correlation between the $\mathrm{pH}$ and number of $\mathrm{H}^{+}$ions on the adsorbent surface. In acidic condition in which the $\mathrm{pH}$ is low, the number of $\mathrm{H}^{+}$ions on the adsorbent surface is high, so electrostatic attraction increases between positively charged adsorbent surface and negatively charged dexamethasone ions. In neutral and alkaline conditions $\left(\mathrm{pH} \geq 7\right.$ ), the number of $\mathrm{H}^{+}$ions is low. In these cases, $\mathrm{OH}^{-}$ions and contaminant anions compete together for placing on adsorbent surface, so the removal efficiency decreases (Khalfaouei and Meniai 2012).

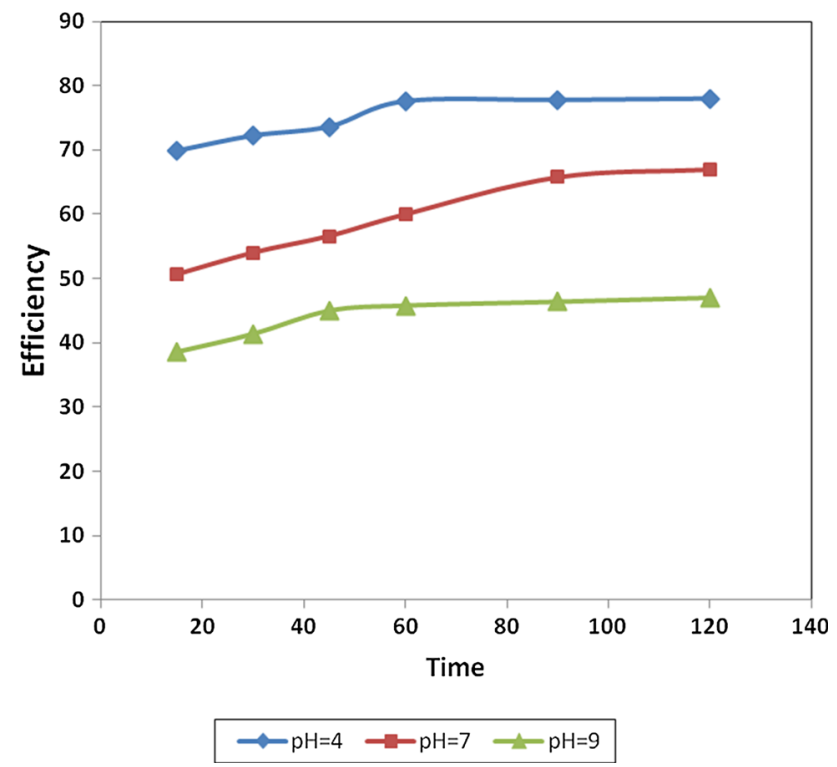

Fig. 2 Effect of $\mathrm{pH}$ on dexamethasone removal. Dexamethasone concentration $=5 \mathrm{mg} / \mathrm{l}$ and adsorbent dose $=0.5 \mathrm{~g}$

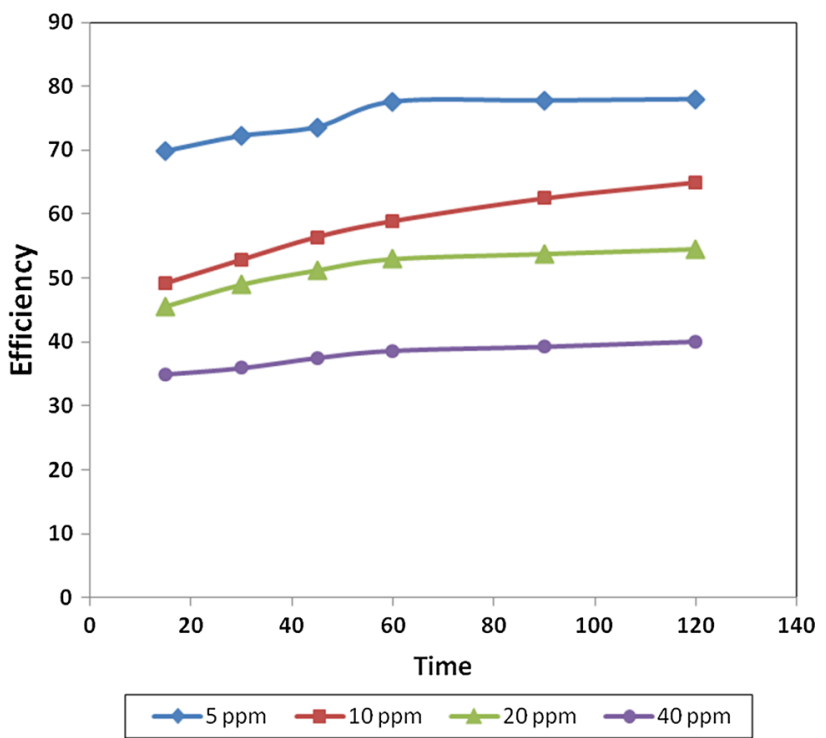

Fig. 3 Effect of initial concentration on dexamethasone removal. $\mathrm{pH}=4$ and adsorbent dose $=0.5 \mathrm{~g}$

\section{Effect of initial dexamethasone concentration on adsorption}

In the current study, the experiments were done at different initial concentrations $(5,10,20$ and $40 \mathrm{mg} / \mathrm{l})$ to determine the effect of initial dexamethasone concentration on 
removal efficiency. As shown in Fig. 3, by increasing the initial concentration, the removal efficiency was decreased, while the adsorption capacity was increased (Jain et al. 2009a). At low concentrations, the ratio of the available surface to the initial concentration is large; therefore, the removal efficiency is high. However, when the adsorbate concentration increases, this ratio reduces, so the removal efficiency decreases, too (Jain et al. 2009b; Jalali and Aboulghazi, 2013).

\section{Effect of adsorbent dose on adsorption efficiency}

In this study, the effect of adsorbent dose on removal efficiency was investigated through varying the adsorbent dose $(0.1,0.3$ and $0.5 \mathrm{~g} / 50 \mathrm{ml})$ in the aqueous solutions. Results in Fig. 4 demonstrate that when adsorbent dose increases, removal efficiency increases but adsorption capacity decreases (Bhaumik et al. 2011; Lian et al. 2013). The increase in removal efficiency can be explained as when the adsorbent dose is increased, the number of exchangeable sites and the amount of surface area are increased, too. The decrease in adsorption capacity may be owing to the overlapping of adsorption sites resulted from overcrowding of adsorbent particles (Garg et al. 2004).

\section{Scanning electron microscopy (SEM)}

The surface morphology of the adsorbent before and after the adsorption process was conducted with the help of SEM. As represented in Fig. 5a, an electron micrograph of native $\mathrm{CP}$ shows that its surface is irregular and porous, and there is a good probability for dexamethasone to be

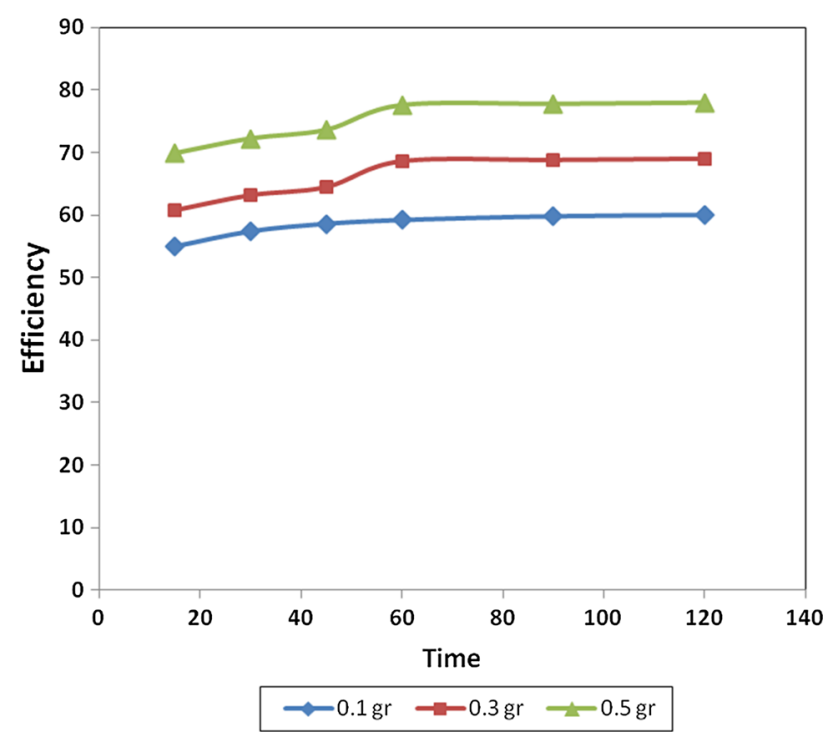

Fig. 4 Effect of adsorbent dose on dexamethasone removal. Dexamethasone concentration $=5 \mathrm{mg} / \mathrm{l}$ and $\mathrm{pH}=4$
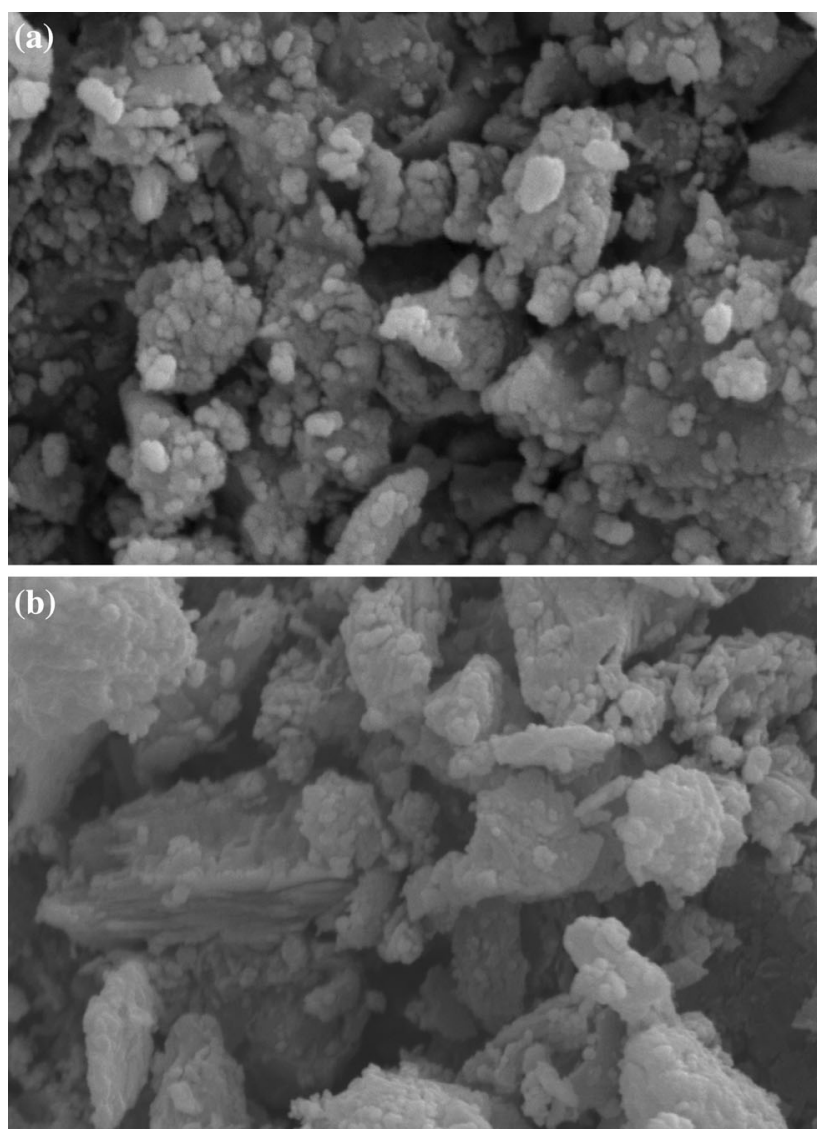

Fig. 5 SEM photographs of modified CP (a) and dexamethasoneloaded modified CP (b)

adsorbed into these pores. It is evident from the SEM of dexamethasone-loaded CP (Fig. 5b) that its surface has become shiny due to the deposition of dexamethasone ions after adsorption (Jain et al. 2009b).

\section{Sorption kinetics}

The kinetic of adsorption demonstrates the rate of dexamethasone removal by the adsorbent, and this rate determines the equilibrium time. Kinetic models were used to characterize the mechanism of adsorption and specify the adsorbent performance. This model depends on different factors such as physical and chemical properties of the adsorbent and mass transfer process. In this study, the kinetic of the adsorption process was analyzed using pseudo-first-order and pseudo-second-order equations given below:

$\ln \left(q_{\mathrm{e}}-q_{\mathrm{t}}\right)=\ln \left(q_{\mathrm{e}}\right)-k t$

$\frac{t}{q_{\mathrm{t}}}=\frac{1}{k}+\frac{t}{q_{\mathrm{e}}}$

As shown in Fig. 6, the correlation coefficient $\left(R^{2}\right)$ in the pseudo-first-order model is relatively low; therefore, 


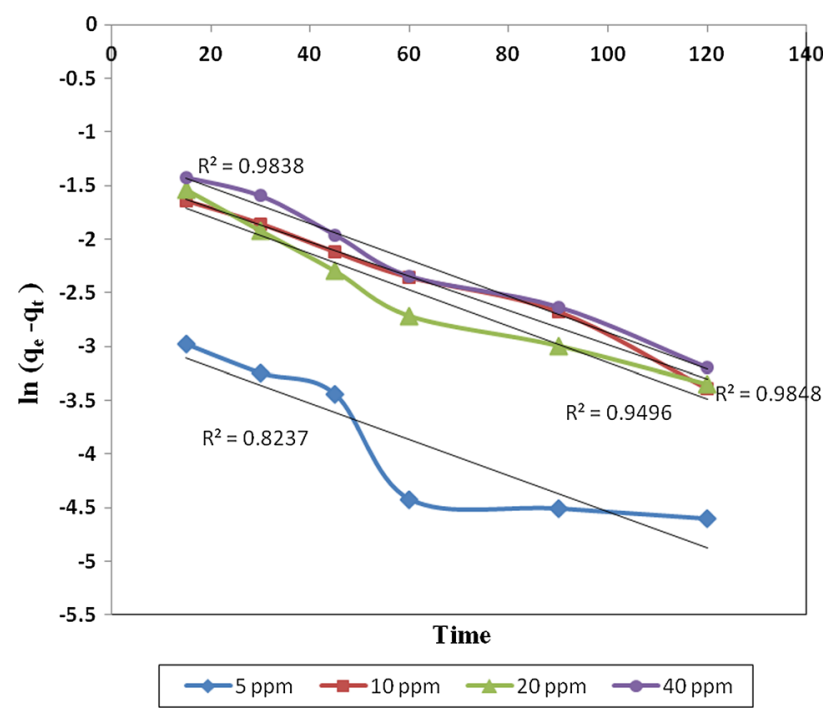

Fig. 6 Pseudo-first-order kinetic model

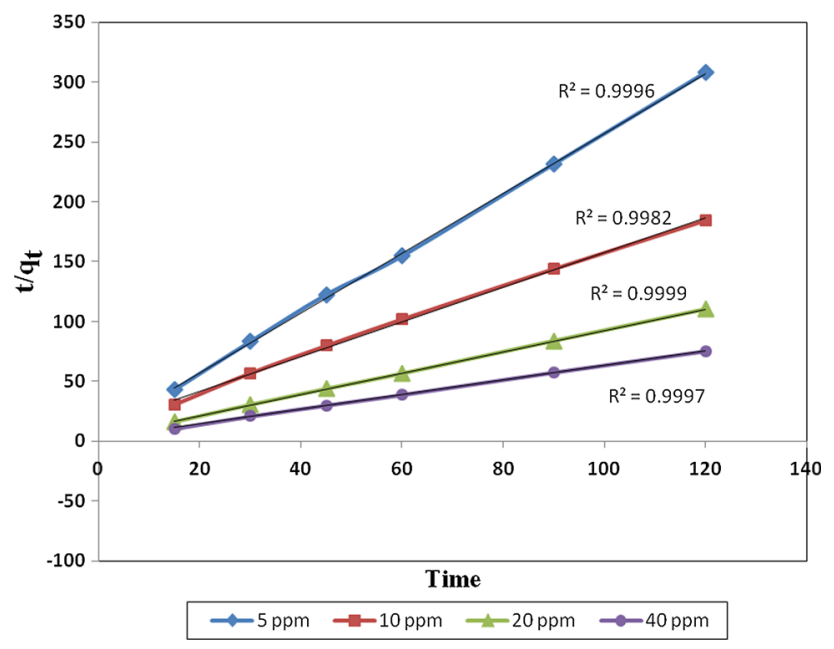

Fig. 7 Pseudo-second-order kinetic model

this model is inappropriate. Considering Fig. 7, it is obvious that the correlation coefficient is very high in the pseudo-second-order model; therefore, this model presents a suitable dexamethasone removal through $\mathrm{CP}$ zeolite.

In the adsorption process, there is a logic that the adsorbate removed from the solution is found in or on the adsorbent. Therefore, in this study, we can determine the retention of dexamethasone using modified zeolite with a simple mass balance as below:

$q=\frac{V\left(C_{\mathrm{i}}-C_{\mathrm{eq}}\right)}{M}$

where $q(\mathrm{mg} / \mathrm{g})$ is dexamethasone retention by the adsorbent, $V(\mathrm{~L})$ is the volume of liquid phase, $C_{\mathrm{i}}$ and $C_{\text {eq }}(\mathrm{mg} / \mathrm{l})$ are the initial and equilibrium concentrations of the dexamethasone, respectively, and $M(g)$ is the mass of the adsorbent.

\section{Sorption isotherm}

Adsorption isotherms express the relationship between adsorption capacity $(q)$ and final concentration of adsorbate $\left(C_{\mathrm{eq}}\right)$ and provide important data for designing adsorption systems. In the present study, four isotherms including Freundlich, Langmuir, Temkin and Sips were used to describe sorption equilibrium data.

The Freundlich isotherm assumes that the adsorbent has a heterogeneous surface and the removal of contaminant ions occurs using multilayer adsorption. In this isotherm, the removal efficiency, because of having multilayer adsorption, rises with the increase in contaminant concentration (Jain et al. 2009a). The linearized Freundlich model is expressed as:

$\ln \left(q_{\mathrm{e}}\right)=\ln \left(k_{\mathrm{f}}\right)+\frac{1}{n} \ln \left(C_{\mathrm{e}}\right)$

where $q_{\mathrm{e}}(\mathrm{mg} / \mathrm{g})$ is adsorption capacity at equilibrium, and $C_{\mathrm{e}}(\mathrm{mg} / \mathrm{L})$ is the equilibrium concentration of dexamethasone in the solution. All factors that affect the adsorption process are incorporated in $k_{\mathrm{f}}$ and $n$ constants. Values of $k_{\mathrm{f}}$ and $n$ were calculated from the intercept and slope of the plot of $\ln \left(q_{\mathrm{e}}\right)$ versus $\ln \left(C_{\mathrm{e}}\right)$ and are illustrated in Table 2.

The Langmuir model assumes that the adsorbent has a homogeneous surface and removal of contaminant ions occurs using monolayer adsorption and there is no interaction between adsorbed ions (Jain et al. 2009a). The linearized Langmuir model is represented by the following equation:

$\frac{C_{\mathrm{e}}}{q_{\mathrm{e}}}=\frac{1}{q_{\mathrm{m}} k}+\frac{C_{\mathrm{e}}}{q_{\mathrm{m}}}$

where $q_{\mathrm{e}}(\mathrm{mg} / \mathrm{g})$ is adsorption capacity at equilibrium, $q_{\mathrm{m}}$ $(\mathrm{mg} / \mathrm{g})$ is the maximum adsorption capacity and $C_{\mathrm{e}}(\mathrm{mg} / \mathrm{L})$ is the equilibrium concentration of dexamethasone in the solution, whereas $k$ is the Langmuir constant. The values of $q_{\mathrm{m}}$ and $k$ were calculated from the slope and intercept of the plot of $C_{\mathrm{e}} / \mathrm{q}_{\mathrm{e}}$ versus $C_{\mathrm{e}}$ and are reported in Table 2.

In the Langmuir isotherm, there is an essential characteristic that can be explained in terms of a dimensionless constant separation factor $\left(R_{\mathrm{L}}\right)$ defined as:

$R_{\mathrm{L}}=\left(\frac{1}{1+k C_{\mathrm{i}}}\right)$

where $C_{\mathrm{i}}(\mathrm{mg} / \mathrm{L})$ is the initial concentration of dexamethasone, and $k$ is the Langmuir constant. $R_{\mathrm{L}}$ is a positive number and determines the feasibility of the adsorption process (Jain et al. 2009a). For a favorable adsorption in 
Table $1 R_{\mathrm{L}}$ for different concentrations at optimal conditions $(\mathrm{pH}=4,0.5 \mathrm{~g}$ zeolite)

Table 2 Freundlich, Langmuir, Temkin and Sips parameters at optimal conditions $(\mathrm{pH}=4$, $0.5 \mathrm{~g}$ zeolite)

\begin{tabular}{ll}
\hline$C_{\mathrm{i}}(\mathrm{mg} / \mathrm{l})$ & $R_{\mathrm{L}}$ \\
\hline 5 & 0.552 \\
10 & 0.381 \\
20 & 0.235 \\
40 & 0.133 \\
\hline
\end{tabular}

\begin{tabular}{lc}
\hline Freundlich model & \\
$k_{\mathrm{f}}$ & 0.372 \\
$n$ & 2.15 \\
$R^{2}$ & 0.996 \\
Langmuir model & \\
$q_{\mathrm{m}}$ & 1.976 \\
$k$ & 0.162 \\
$R^{2}$ & 0.982 \\
Tempkin model & \\
$A_{\mathrm{T}}$ & 1.96 \\
$b_{\mathrm{T}}$ & 6272.33 \\
$R^{2}$ & 0.966 \\
Sips model & \\
$k_{\mathrm{S}}$ & 1.54 \\
$a_{\mathrm{S}}$ & 4.128 \\
$\beta_{\mathrm{S}}$ & 0.465 \\
$R^{2}$ & 0.996 \\
\hline
\end{tabular}

each initial concentration of the contaminant, the $R_{\mathrm{L}}$ values must be between 0 and 1 (Jain et al. 2009b). The $R_{\mathrm{L}}$ values for adsorption of dexamethasone on modified $\mathrm{CP}$ in different concentrations are represented in Table 1.

The Temkin isotherm model assumes that the heat of adsorption of all molecules decreases linearly rather than logarithmically with coverage because of the interactions between the adsorbent and adsorbate and the adsorption is characterized by a uniform distribution of binding energies (Kundu and Gupta, 2006). The linearized form of the Temkin isotherm can be expressed by the following equation:

$q_{\mathrm{e}}=\frac{R T}{b_{\mathrm{T}}} \ln \left(A_{\mathrm{T}}\right)+\frac{R T}{b_{\mathrm{T}}} \ln \left(C_{\mathrm{e}}\right)$

where $R$ is universal gas constant $(8.314 \mathrm{~J} / \mathrm{mol} \mathrm{K})$ and $T$ is temperature $(298 \mathrm{~K})$, whereas $A_{\mathrm{T}}$ and $b_{\mathrm{T}}$ are Temkin constants. The values of $A_{\mathrm{T}}$ and $b_{\mathrm{T}}$ were calculated from the slope and intercept of the plot of $q_{\mathrm{e}}$ versus $\ln C_{\mathrm{e}}$ and are reported in Table 2.

The Sips isotherm model is a combination of the Langmuir and Freundlich models. When the adsorbate concentration is low, it follows the Freundlich model, but at high adsorbate concentrations, it leads to the Langmuir model and predicts a monolayer adsorption. The linearized form of the Sips isotherm can be represented by the following equation:

$\ln \frac{k_{\mathrm{S}}}{q_{\mathrm{e}}}=-\beta_{\mathrm{S}} \ln C_{\mathrm{e}}+\ln a_{\mathrm{S}}$

where $k_{\mathrm{S}}(\mathrm{L} / \mathrm{g}), a_{\mathrm{S}}(\mathrm{L} / \mathrm{mg})$ and $\beta_{\mathrm{S}}$ are Sips isotherm model constants. The operating conditions such as $\mathrm{pH}$ solution, temperature and concentration of adsorbate affect the equation parameters (Foo and Hameed, 2010). The values of $a_{\mathrm{S}}$ and $\beta_{\mathrm{S}}$ were calculated from the intercept and slope of the plot of $\ln \left(\frac{k \mathrm{~s}}{q_{\mathrm{e}}}\right)$ versus $\ln C_{\mathrm{e}}$ and are reported in Table 2 .

\section{Conclusion}

Due to resistant structure of dexamethasone against the biological degradation and its low concentration in hospital wastewater, the decomposition of this compound by conventional wastewater treatment plants is very difficult. In the current study, the use of modified $\mathrm{CP}$ as a natural adsorbent for the purpose of removing dexamethasone from aqueous solutions was investigated. The high removal efficiency, natural and inexpensive, not production of sludge and other harmful substances for the environment (environmental friendly), are the advantages of this adsorbent. The removal efficiency depends on the $\mathrm{pH}$ solution, initial concentration of dexamethasone, adsorbent dose and contact time. The experimental data were fitted with the Freundlich and Sips models well. Maximum removal of dexamethasone was occurred in $\mathrm{pH}=4$ with $0.5 \mathrm{~g} \mathrm{CP}$.

Acknowledgments The authors would like to express their gratitude to the Research Deputy of the Mazandaran University and Babol University of Medical Sciences.

\section{References}

Acheampong MA, Pakshirajan K, Annachhatre AP, Lens P (2013) Removal of $\mathrm{Cu}$ (II) by biosorption onto coconut shell in fixed-bed column systems. J Ind Eng Chem 19(3):841-848

Al-Dujaili AH, Awwad M, Salem NM (2012) Biosorption of cadmium (II) onto loquat leaves (Eriobotrya japonica) and their ash from aqueous solution, equilibrium, kinetics, and thermodynamic studies. Int J Ind Chem 3:22-29

Amouei AI, Ehrampoush MH, Ghaneian MT, Asgharzadeh F, Mousapour A, Parsian H (2014) Removing cadmium from aqueous solutions by the canola residuals. J Mazand Univ Med Sci 23(110): 154-163

Amuda OS, Ibrahim AO (2006) Industrial wastewater treatment using natural material as adsorbent. Afr J Biotechnol 5(16):1483-1487

APHA, AWWA, WEF (2012) Standard methods for examination of water and wastewater, 22nd edn. American Public Health Association, Washington, p 1360 
Arsand DR, Kümmerer K, Martins F (2013) Removal of dexamethasone from aqueous solution and hospital wastewater by electrocoagulation. Sci Total Environ 443:351-357

Bhaumik M, Leswifi T, Maity A, Srinivasu V, Onyango M (2011) Removal of fluoride from aqueous solution by polypyrrole/ Fe3O4 magnetic nanocomposite. J Hazard Mater 186:150-159

Blazquez G, Martín-Lara MA, Dionisio-Ruiz E, Tenorio G, Calero M (2012) Copper biosorption by pine cone shell and thermal decomposition study of the exhausted biosorbent. J Ind Eng Chem 18(5):1741-1750

Cerino Cordova FJ, Diaz Flores PE, Garcia Reyes RB (2013) Biosorption of $\mathrm{Cu}(\mathrm{II})$ and $\mathrm{Pb}$ (II) from aqueous solutions by chemically modified spent coffee grains. Int $\mathrm{J}$ Environ Sci Technol 10:1399-1400

Chutia P, Kato S, Kojima T, Satokawa S (2009) Adsorption of As(V) on surfactant-modified natural zeolites. J Hazard Mater 162:204-211

Dianati Tilaki RA, Kavyani S, Hassani Nejad-Darzi SK, Yazdani Cherati J (2014) Kinetics study on adsorption of three azo dyes (Reactive Red 198, Cationic Red GRL 18 and Cationic Red GRL 46) by zeolite clinoptilolite. J Mazandaran Univ Med Sci 24(118):158-169

Elwakeel K, Guibal E (2015a) Arsenic(V) sorption using chitosan/ $\mathrm{Cu}(\mathrm{OH})_{2}$ and chitosan/CuO composite sorbents. Carbohydr Polym 134:190-204

Elwakeel K, Guibal E (2015b) Selective removal of $\mathrm{Hg}(\mathrm{II})$ from aqueous solution by functionalized magnetic-macromolecular hybrid material. Chem Eng J 281:345-359

Fiol N, Villaescusa I, Martinez M, Miralles N, Poch J, Serarols J (2006) Sorption of $\mathrm{Pb}(\mathrm{II}), \mathrm{Ni}(\mathrm{II}), \mathrm{Cu}(\mathrm{II})$ and $\mathrm{Cd}(\mathrm{II})$ from aqueous solution by olive stone waste. Sep Purif Technol 50:132-140

Foo KY, Hameed BH (2010) Insights into the modeling of adsorption isotherm systems: a review. Chem Eng J 156:2-10

Garg V, Gupta R, Kumar R, Gupta RK (2004) Adsorption of chromium from aqueous solution on treated sawdust. Bioresour Technol 92:79-81

Ghiaci M, Kiaa R, Abbaspur A, Seyedeyn-Azad F (2004) Adsorption of chromate by surfactant-modified zeolites and MCM-41 molecular sieve. Sep Purif Technol 40:285-295

Heberer T (2002) Occurrence, fate and removal of pharmaceutical residues in the aquatic environment: a review of recent research data. Toxicol Lett 131:5-17

Herrero P, Borrul F, Pocurull P, Marce R (2012) Determination of Glucocorticoids in sewage and river waters by ultra-high performance liquid chromatography-tandem mass spectrometry. J Chromatogr A 1224:19-26

Jafari M, Aghamiri SF, Khaghanic G (2011) Batch adsorption of cephalosporins antibiotics from aqueous solution by means of multi-walled carbon nanotubes. World Appl Sci J 14:1642-1650

Jain M, Garg VK, Kadirvelu K (2009a) Chromium(VI) removal from aqueous system using Helianthus annuus (sunflower) stem waste. J Hazard Mater 162:365-372
Jain M, Garg VK, Kadirvelu K (2009b) Equilibrium and kinetic studies for sequestration of $\mathrm{Cr}(\mathrm{VI})$ from simulated wastewater using sunflower waste biomass. J Hazard Mater 171:328-334

Jaishankar M, Mathew B, Sailesh Shah M, Murthy K, Gowda S (2014) Biosorption of few heavy metal ions using agricultural wastes. J Environ Pollut Hum Health 2:1-6

Jalali M, Aboulghazi F (2013) Sunflower stalk, an agricultural waste, as an adsorbent for the removal of lead and cadmium from aqueous solutions. J Mater Cycles Waste Manag 15:548-555

Keshtkar A, Hassani M (2014) Biosorption of thorium from aqueous solution by $\mathrm{Ca}$-pretreated brown algae Cystoseira indica. Korean J Chem Eng 31(2):289-295

Khalfaouei A, Meniai A (2012) Application of chemically modified orange peels for removal of copper (II) from aqueous solutions. Theor Found Chem Eng 46(6):732-739

Kummerer K (2001) Drugs in the environment: emission of drugs, diagnostic aids and disinfectants into wastewater by hospitals in relation to other sources: a review. Chemosphere 45:957-969

Kundu S, Gupta A (2006) Arsenic adsorption onto iron oxide-coated cement (IOCC): regression analysis of equilibrium data with several isotherm models and their optimization. Chem Eng J 122:93-106

Li Z (2007) Removal of cationic surfactants from water using clinoptilolite zeolite. The 40th Anniversary of International Zeolite Conference

Li C, Zhong H, Wang S, Xue J, Zhang Z (2015) Removal of basic dye (methylene blue) from aqueous solution using zeolite synthesized from electrolytic manganese residue. J Ind Eng Chem 23:344-352

Lian A, Xuegang L, Xiaoyan L, Sizhao Z (2013) Biosorption behaviors of uranium (VI) from aqueous solution by sunflower straw and insights of binding mechanism. J Radioanal Nucl Chem 298:1823-1834

Maleki A, Daraei H, Zandsalimi Y, Rezaee R, Safari M, Bahmani P (2015) Natural and acid modified clinoptilolite for adsorption of aqueous direct dye: parameters, isotherm and kinetic. In: Proceedings of the 14th international conference on environmental science and technology Rhodes, Greece, 3-5 September

Malekpour A, Hajialigol S, Taher M (2009) Study on solid-phase extraction and flame atomic absorption spectrometry for the selective determination of cadmium in water and plant samples with modified clinoptilolite. J Hazard Mater 172:229-233

Reid I (2000) Glucocorticoid-induced osteoporosis. Best Pract Res Clin Endocrinol Metab 14:279-298

Schäcke H, Döcke W, Asadullah K (2002) Mechanisms involved in the side effects of glucocorticoids. Pharmacol Ther 96:23-43

Sharma P, Kaur H, Sharma M, Sahore V (2011) A review on applicability of naturally available adsorbents for the removal of hazardous dyes from aqueous waste. Environ Monit Assess 183:151-195

Sim W, Lee J, Oh J (2010) Occurrence and fate of pharmaceuticals in wastewater treatment plants and rivers in Korea. Environ Pollut 158:1938-1947 
Sui Q, Huang J, Deng D, Yu G, Fan Q (2010) Occurrence and removal of pharmaceuticals, caffeine and DEET in wastewater treatment plants of Beijing, China. Water Res 44:417-426

Vasylechko VO, Gryshchouk G, Kuzma Y, Zakordonskiy V, Lebedynets L, Kalytovska M (2003) Adsorption of cadmium on acid-modified Transcarpathian clinoptilolite. Microporous Mesoporous Mater 60:183-196
Wibowo W, Utari T, Yunarti RT (2011) Anion exchange capacity of chromate on modified zeolite clinoptilolite with HDTMA-Br and its regeneration. Makara Sains 15:53-57

Yusof AM, Malek N (2009) Removal of Cr(VI) and As(V) from aqueous solutions by HDTMA-modified zeolite Y. J Hazard Mater 162:1019-1024 